\title{
PARAMETRIC STUDY OF THE EFFECT OF CROSS-FRAMES ON THE BEHAVIOUR OF COMPOSITE STEEL-CONCRETE GIRDERS CURVED IN PLAN AND CONSTRUCTED WITH SHORING
}

\author{
Mohamed Abdel-Basset Abdo \\ Civil Engineering Department, Faculty of Engineering, Assiut University, \\ Assiut, Egypt.

\section{Waleed Abo El-Wafa Mohamed} \\ Civil Engineering Department, Faculty of Engineering, Assiut University, \\ Assiut, Egypt.
}

\section{(Received July 4, 2006 Accepted July 27, 2006)}

The use of cross frames in bridge is provided to act together with the longitudinal girders to form a system that behaves as a unit. In horizontally curved bridges, the interaction of bending and torsion causes these components to become major load-carrying elements (primary members) and not secondary members as that in straight girders. This study is concerned with parametric study of the effect of cross frames on the behaviour of composite steel-concrete girders curved in plan using finite element technique. Shoring is assumed to be used during construction and both dead and live loads according to ECP are taken into consideration in the analysis. The concrete deck slab and both steel webs and flanges are modeled using shell elements. However, both studs and cross frames are modeled using beam elements. The study includes not only the displacements but also the tangential stresses through the inner edge, middle and outer edge of the tension flange along the span of the critical outside girder. Based on the numerical results it is shown that slenderness ratio of cross frames, cross frame spacing, radius of curvature, span length and flange width have greatest effect on the warping-to-bending stress ratio. It is shown that equations which can be used for composite girders subjected to noncomposite dead loads and recommended by other authors may give inaccurate results for curved composite systems constructed with shoring. Also, they do not take the slenderness ratio of cross frames into consideration. Two equations are proposed for the preliminary design of cross frame spacing and warping-to-bending stress ratio for curved composite systems constructed with shoring. The accuracy of the results using the new equations is checked for various variables. From equations, it is recommended that the maximum slenderness ratio of cross frames should not exceed 140. Also, the distance between cross frames should be ranged from 3 to $5 \mathrm{~m}$.

KEYWORDS: Parametric study, cross frames, composite steel-concrete girders, horizontally curved bridges and shoring. 


\section{INTRODUCTION}

Constant need for cost-effective structural forms has led to the increasing use of composite construction. Significant economy has been observed in this form of construction, especially in bridges and building floors. Eliminating or minimizing the slip at the interface of steel and concrete members ensures the composite action. The resulting increase in strength and stiffness will depend on the extent to which the slip is prevented. One way of achieving the bond between the steel girder and the deck slab is by welding the shear connectors to the upper flange of the steel girder. These shear connectors provide anchorage for the concrete slab and prevent the movement between the deck slab and the steel girder. A concrete slab, which is necessary to support the area loads, acquires an additional function; i.e. it forms the compression chord of the composite cross section. The tensile bending stresses are borne by the steel beam. A higher degree of stiffness thus ensures minimal deflection. Thus, the composite construction results in: 1) saving in structural steel weight; 2) on a static ultimate loads basis, an increase in the overload capacity over that of a non-composite construction; and 3) for a given load, a reduction in construction depth with consequent saving in embankment costs for bridges or story heights in buildings, [1].

Horizontally curved bridges have become an important component in highway systems, especially in densely populated cities such as Cairo and Alexandria in Egypt. Indeed, horizontally curved bridges offer the following advantages over bridges built from a series of straight girder chords: 1) fewer substructure units (piers) are required, 2) less land space is needed, and 3) traffic design speeds can be maintained. Moreover the shape of horizontally curved bridges is more aesthetically pleasing than the shape of similar chorded structures. Such bridges may be entirely constructed of reinforced concrete, prestressed concrete, or composite concrete deck on steel I- or box girders. Curved steel I-girder bridges are the preferred choice because of its simplicity of fabrication and construction, fast speed of erection, and excellent serviceability performance. I-shaped girder bridges are relatively strong and stiff under service loading and the behaviour gravitates towards that of a multi-cell box section when adequately provided with diaphragms and cross frames, [2].

The use of diaphragms and cross frames in bridge design has gained general acceptance. Usually, a series of diaphragms act together with the longitudinal beams or girders to form a system that behaves as a unit. In straight right-angled bridges, cross frames and diaphragms act as secondary members in maintaining structural integrity. Diaphragms or cross frames are provided at intervals not to exceed $8 \mathrm{~m}$ or $25 \mathrm{ft}$. However, in horizontally curved and skewed bridges, the interaction of bending and torsion causes these components to become major load-carrying elements (primary members). There is a growing sentiment in the bridge engineering community to eliminate or at least minimize the number of cross frames due to the added cost and adverse fatigue problems, [3].

Numerous works have been published concerning the behaviour of horizontally curved composite steel-concrete girders, e.g., [2], [4] and [5]. However, analytical design-oriented research concerning the cross-frame requirements of horizontally curved bridges is limited. Schelling et al. [6] have used the equivalent 
truss system to simulate the girders and cross frames where the flanges and web of the girders are replaced with equivalent truss members. With a system of girders and cross frames modeled in this manner, the deformation of the web is not accounted. Heins and Jin [7] have indicated that this deformation may have a considerable effect on deflections and stresses. On the other hand, Yoo and Littrell [8] have studied the effect of cross bracing on curved girders. They used shell elements to model the web of the steel beam. They derived an equation for the preliminary design of cross frame spacing for curved I-girder bridges. Unfortunately, they neglected a potential parameter such as the flange width. Davidson et al. [9] have also investigated the effect of cross frame spacing for curved I-girder composite bridges. They considered the effect of a number of variables on the response of the curved girder systems. They recommended using two equations for the preliminary design of cross frame spacing for curved I-girder bridges for non-composite dead loads. However, they used beam elements (not shell elements) to model the flanges and they did not take the effect of cross frame stiffness into consideration. That's why their equations are in need to be checked for bridges constructed with shoring.

The objective of this paper is to investigate the influence of different major parameters of cross frames affecting the response of curved composite girders constructed with shoring in the elastic range of loading. Also, to develop an equation for the warping-to-bending stress regarding the cross frame spacing for the preliminary design of curved composite girders. The present study considers the effect of a number of design variables on the response of the curved girder systems including stiffness of cross frames, cross frame spacing, degree of curvature, flange width, girder spacing and number of girders. Both web and flanges are modeled as shell elements. A careful numerical study is carried out by using the finite element method to analyze the behaviour of composite girders curved in plan. The accuracy of numerical results is verified via a comparison with experimental results by other researchers.

\section{THEORETICAL BACKGROUND [9]}

\subsection{Stress Distribution In Curved Beams}

It is well known that horizontally curved I-girders undergo a coupled lateralbending moment of the top and bottom flanges due to curvature, termed the torsional warping moment or "bimoment" which induces warping of the girder cross section as shown in Fig. 1. For curved I-girder bridge system under gravity loading where the rotation of the cross section is restrained by connecting cross frames or diaphragms, the bimoment and thus lateral bending of the flanges, varies dramatically in magnitude and direction along the span with lateral moment peaks generally occurring at the crossframe locations. At the cross frame locations, the bimoment increases the normal stresses on the outside of curvature edge and decreases stress on the inside. In the intervals between cross frames, the direction of the bimoment is reversed and the highest stresses occur on the inside edge of the flanges. The individual and combined normal stress distribution in the flanges due to major axis bending and bimoment are shown in Fig. 2. 

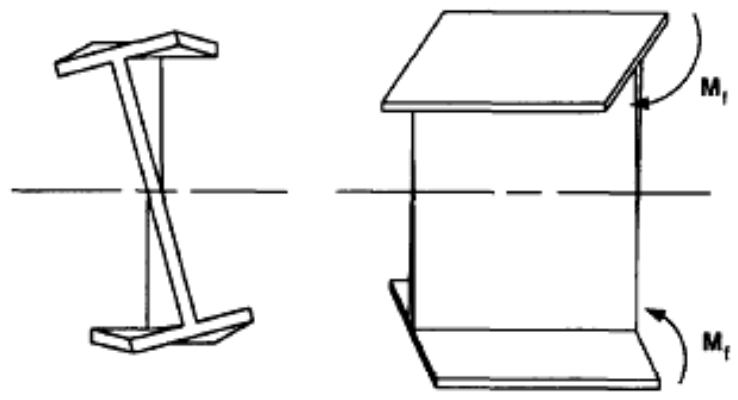

Figure 1: Warping of cross section.

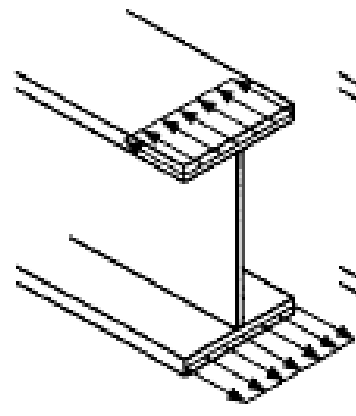

(a)

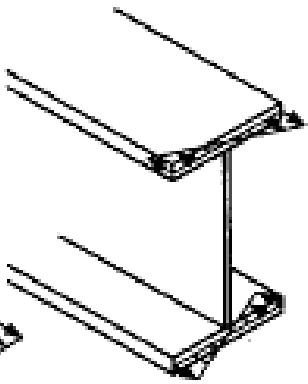

(b)

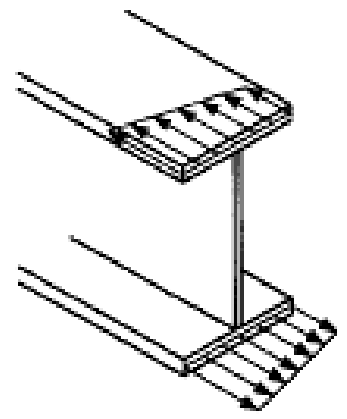

(c)

Figure 2: Normal stress distribution in curved I-girder flanges: (a) major axis bending stress; (b) warping stress; (c) combined bending and warping stress

\subsection{Cross-Frame Spacing Equations}

For simplicity, consider the following approach based on the behaviour of a single horizontally curved beam. Under gravity loads and with the area of the flanges much larger than that of the web, the tangential force $P$ in the flanges due to vertical moments can be approximated by

$$
P=\sigma_{b} b_{f} t_{f}=M_{v} / d,
$$

where $P=$ normal stress resultant in the flange due to vertical moment; $M_{v}=$ vertical (major axis) bending moment; $d=$ girder depth; $\sigma_{b}=$ normal stress in flange due to vertical bending; $b_{f}=$ flange width; and $t_{f}=$ flange thickness.

If the flange is curved with a radius $R$, radial components $F_{r}$ of the internal forces $P$ are developed as shown in Fig. 3(a), designated as flange distributed load $q$. The magnitude of $q$ is obtained from the equilibrium condition of a very small segment of the girder with subtended angle $d \phi$ and arc length $d s$, as shown in Fig. 3(a). It is important to mention that $q$ and $P$ vary along the girder length, but for a very small segment they may be considered constant. Equilibrium requires:

$$
\begin{aligned}
& q R d \varphi=P d \varphi, \\
& q=P / R,
\end{aligned}
$$


and the lateral bending or warping stress can be expressed as

$$
\sigma_{w}=M_{f} / S_{f}
$$

where $M_{f}=$ lateral-flange bending moment due to the bimoment; and $S_{f}=$ section modulus of the flange in the horizontal plane. The lateral-section modulus for rectangular flange can be expressed as:

$$
S_{f}=t_{f} b_{f}^{2} / 6
$$

If we consider the flange as a continuous beam with rigid supports (cross frames) at a spacing of $l$ as depicted in Fig. 3(b), the lateral flange bending moment due to virtual load $q$ can be conservatively approximated by

$$
M_{f}=q l^{2} / 10
$$

and the warping or lateral-flange bending stress can be rewritten as

$$
\sigma_{w}=\frac{3}{5} \frac{q l^{2}}{t_{f} b_{f}^{2}}=\frac{3}{5} \frac{\sigma_{b} l^{2}}{R b_{f}} .
$$

Rewriting the preceding relationship in terms of cross-frame spacing $l$, which will reduce the warping-to-bending stress ratio, $F_{w b}$, to a desired level gives

$$
l=\left(\frac{5}{3} F_{w b} R b_{f}\right)^{1 / 2}
$$

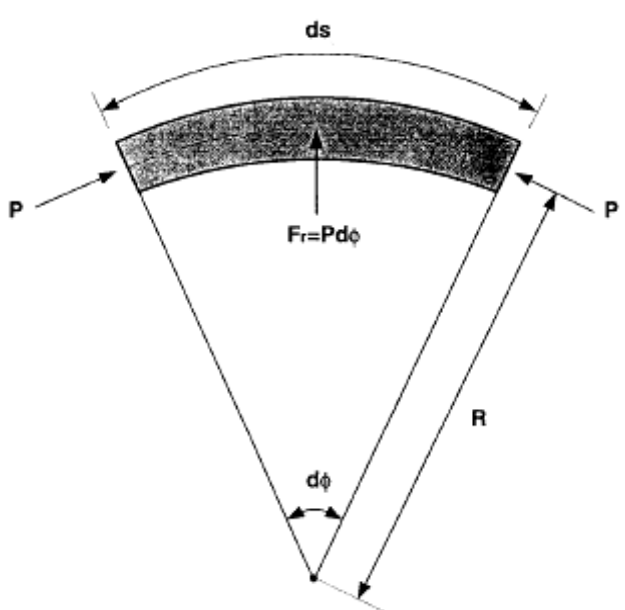

(a)

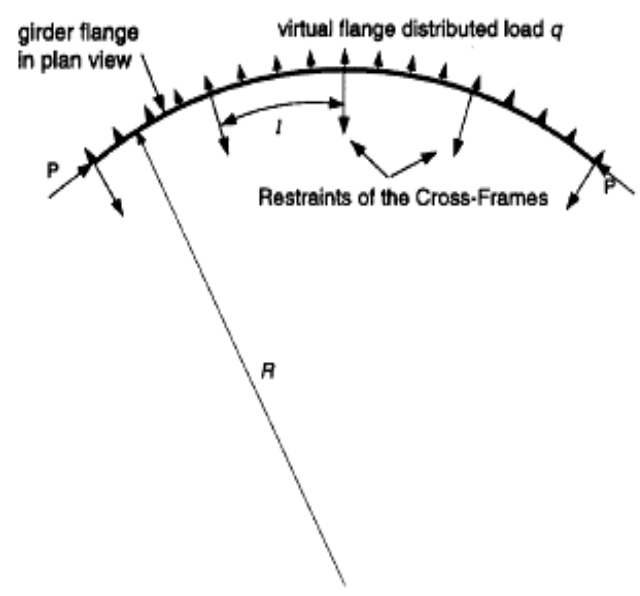

(b)

Figure 3: Plan view of curved flange: (a) small segment of flange;

(b) distributed load analogy. 
Equation (8) has been suggested to get a preliminary design estimate for the cross-frame spacing needed to reduce the warping stresses to an acceptable level, [9]. Another alternative equation is suggested by the same authors as follows:

$$
l=\frac{L}{N}=L\left[-\ln \left(\frac{F_{w b} R b_{f}}{509 L^{2}}\right)\right]^{-1.52}
$$

where $L=$ total span length [m]; $N=$ number of cross-frame intervals; $R=$ radius of curvature [m]; and $b_{f}$ is the flange width [mm]. Davidson et al. [9] demonstrated that Eqs. (8) and (9) are useful in the preliminary design of curved I-girder structures. Herein, the availability of these two equations will be checked on composite steelconcrete girders curved in plan and constructed with shoring. The flange of the steel beam will be modeled as shell elements (not beam elements).

\section{FINITE ELEMENT ANALYSIS}

\subsection{Model Description}

The finite-element modeling in the present study was carried out using the MARC/Mentat package [10], [11]. A three-dimensional finite element model with the following characteristics had been used: (1) a four-node thick shell element with six degrees of freedom at each node (element 75) was used to model the deck slab, steel webs and steel flanges; (2) the offset connection between the tops of the girders and the centre of the deck was modelled using beam elements (element 52). For curved beams, all geometry, boundary conditions and loading conditions were modeled in the cylindrical coordinate system.

The shear connectors between concrete slab and steel flange were modelled by rigid beam elements with a large area but with low bending stiffness. Rigid connection beam elements were used to model the shear studs based on the assumption that no slip occurs between the concrete slab and the steel girder. During the experiments by Thevendran et al. [4], the interfacial slip at both ends between the slab and the top flange of steel girder was measured. The relative displacements at failure were found to be negligibly small for all specimens and the maximum value recorded was 0.09 [mm] and hence the slips could be ignored. The assumption of perfect bonding between the concrete slab and steel beam in the analysis is, therefore, justified.

In present study, the following assumptions are considered: (1) the bridges are simply-supported; (2) the bridges have constant radii of curvature and uniform cross sectional area between support lines; (3) the effects of road super-elevation and curbs are ignored; (4) the reinforced concrete slab deck has complete composite action with the top steel flange of the I-girders; (5) all materials are elastic and homogenous; (6) webs of the steel girders are vertical, and (7) deformations are assumed to remain within the limits of small displacement theory.

\subsection{Convergence Study}

The convergence study for straight and curved composite beams has been carried out on beams that were tested experimentally by Thevendran et al. [4] in order to determine a suitable finite element model for the analysis. A series of five large- 
scale composite beams (SP1-SP5) with span-length to radius of curvature $(L / R)$ ratios ranging from 0.0 to 0.5 were tested to failure under a concentrated load applied at mid span. Each specimen was $6.2 \mathrm{~m}$ long simply supported over a span of $6 \mathrm{~m}$ and consisted of a main girder and three secondary beams (two at the ends to represent diaphragms and one at mid span to apply load). The main girder and secondary girders were made of UB356 $\times 171 \times 57$ (rolled steel beam having overall depth of approximately $356[\mathrm{~mm}]$, flange width of $171 \mathrm{~mm}$ and self weight of $57 \mathrm{~kg} / \mathrm{m}$ ). The concrete slab of all specimens was a normal weight concrete slab with overall thickness of $100 \mathrm{~mm}$. The width of the slab was $1500 \mathrm{~mm}$. The thicknesses of flange and web $=12.9$ and $8 \mathrm{~mm}$, respectively. The experimental results of specimens SP1 (straight) and SP4 (curved) are taken as a reference to check the accuracy of the finite element results. The span-length to radius of curvature for SP4, $L / R=0.25$, i.e., $R=$ $24 \mathrm{~m}$. The automatic load increment of MARC/Mentat was employed and the solution was obtained for load steps of $50 \mathrm{kN}$.

The material properties were: (a) steel: density, $\rho=7850 \mathrm{~kg} / \mathrm{m}^{3}$; yield stress, $\sigma_{y}=360 \mathrm{MPa}$; Young's modulus, $E=210 \mathrm{GPa}$; Poisson's ratio, $v=0.3$ and (b) concrete: density, $\rho=2500 \mathrm{~kg} / \mathrm{m}^{3}$; compressive strength, $30 \mathrm{MPa}$; Young's modulus, $E=25 \mathrm{GPa}$, Poisson's ratio, $v=0.2$. Three independent convergence studies had been carried out on the mesh sizes for concrete slab, steel web, and along the beam span, respectively. The first mesh was 738 elements ( 9 elements along concrete slab width, 2 beam elements for studs, 4 elements for web and 4 elements for each flange and 32 shell elements along the span). The second mesh was 1388 elements (15 elements along concrete slab width, 2 beam elements for studs, 8 elements for web and 4 elements for each flange and 42 shell elements along the span). The third mesh was 2048 elements ( 15 elements along concrete slab width, 2 beam elements for studs, 8 elements for web and 4 elements for each flange and 62 shell elements along the span).

Even though the finite element analysis provides a detailed picture of the deflection profile along the span and stress distribution at a number of locations for different stages of loadings, only a selected set of results is presented for brevity. Figure 4 plots the vertical displacement along the span length of the SP4 for experimental and numerical results with different meshes at stage of loading $=150 \mathrm{kN}$. Generally, good agreement is observed between the experimental and numerical values for all three meshes. It is shown that the finer the mesh the good the results. However, the two curves corresponding to the modeling with 1388 elements and 2048 elements lie very close throughout the loading cycle. Also, the difference between the numerical results and the experimental results for mesh 2 with 1388 elements is less than $1 \%$. Therefore, finite element analysis based on the second mesh seems to be satisfactory for numerical investigation in predicting the elastic behavior of curved composite beam.

\section{BRIDGE GEOMETRY}

The bridge model used in this analysis is one of the existing and newly designed bridges in Egypt [2]. The basic model of the bridge consists of four steel girders, $2 \mathrm{~m}$ spacing between web lines, and length of the bridge is $24 \mathrm{~m}$. The concrete deck is $8 \mathrm{~m}$ width and $25 \mathrm{~cm}$ thickness. The webs of the girders are $130 \times 1.3 \mathrm{~cm}$ 


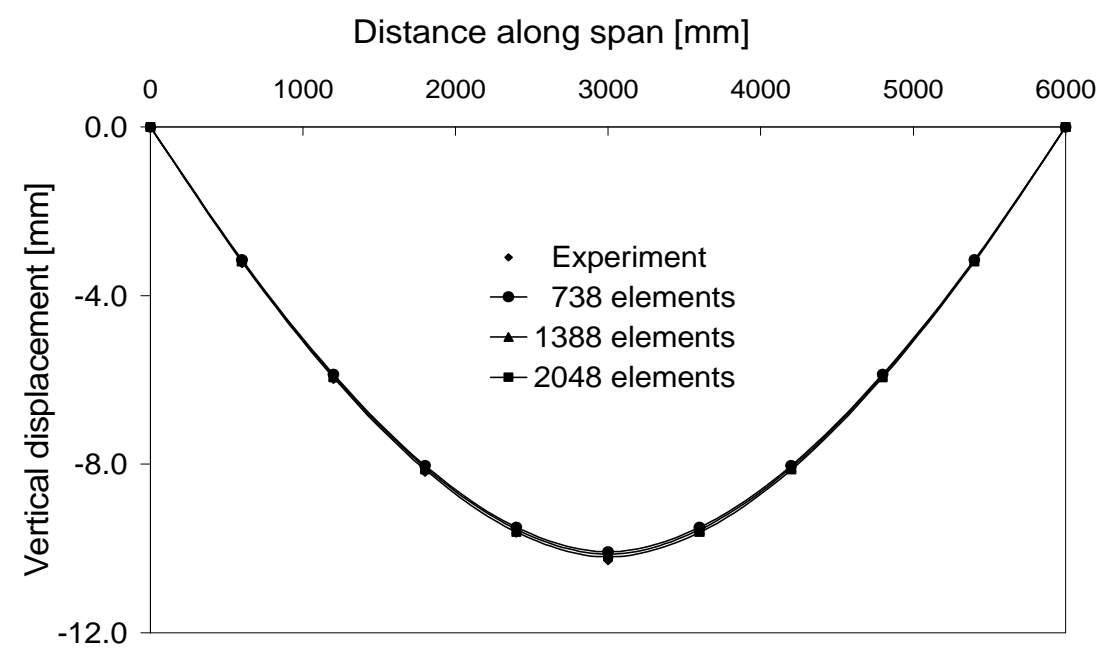

Figure 4: Variation of vertical deflection along the curved length for SP4 under load of 150 [kN] with different meshes.

and top and bottom flanges are $40 \times 4 \mathrm{~cm}$. The steel beams are connected with cross frames of $1 \mathrm{~L} 70 \times 70 \times 7$ spaced at intervals of $4 \mathrm{~m}$ for both straight and curved systems and modelled as beam elements. Only bridges having X-shaped cross diaphragms are considered in the current work. The height of cross frames are 6 shell elements of the web height and each member is divided into 4 elements. A cross section of the finite element model representing this bridge is shown in Fig. 5(a). The material properties are the same as those used in Section 3. Curved bridges with span-to-radius of curvature ratios $L / R$ considered are $0.1,0.3$ and 0.5 , i.e., the radii of curvatures are 240 , 80 and $48 \mathrm{~m}$, respectively. An isometric view of the finite element models is shown in Fig. 5(b), with 5572 nodes and 5916 elements (8 elements for web and 4 elements for each flange and 48 shell elements along the span). One of the supports of the system is hinged (free to rotate about the radial direction) and the other is roller (free to rotate around the radial direction and to translate in the tangential direction).

All models are investigated under dead and live loads. The live load used in this investigation is the ECP [12]. ECP live load consists of: (1) main lane load of 3.0 [m] width which consists of $60 \mathrm{t}(600 \mathrm{kN})$ main truck in addition to leading and trailing uniform load of intensity $500 \mathrm{~kg} / \mathrm{m}^{2}\left(5 \mathrm{kN} / \mathrm{m}^{2}\right)$ on the rest of the lane area. The main lane must be positioned to give maximum straining actions in the bridge superstructure; (2) secondary lane load of $3.0 \mathrm{~m}$ width which consists of $30 \mathrm{t}(300 \mathrm{kN})$ secondary truck in addition to leading and trailing uniform load of intensity $300 \mathrm{~kg} / \mathrm{m}^{2}\left(3 \mathrm{kN} / \mathrm{m}^{2}\right)$ on the rest of the lane area; (3) the rest of the bridge carriage way is covered with a uniform load of intensity $300 \mathrm{~kg} / \mathrm{m}^{2}\left(3 \mathrm{kN} / \mathrm{m}^{2}\right)$. The dynamic load factor " $\boldsymbol{I}$ " is calculated using the following roadway bridge impact formula "I $=\mathbf{0 . 4}-\mathbf{- 0 . 0 0 8 L}$ "; where $L$ is the beam span length in $\mathrm{m}$. Only the main lane load (truck + uniform) is to be magnified by the impact (dynamic) factors, neither the secondary lane load nor 


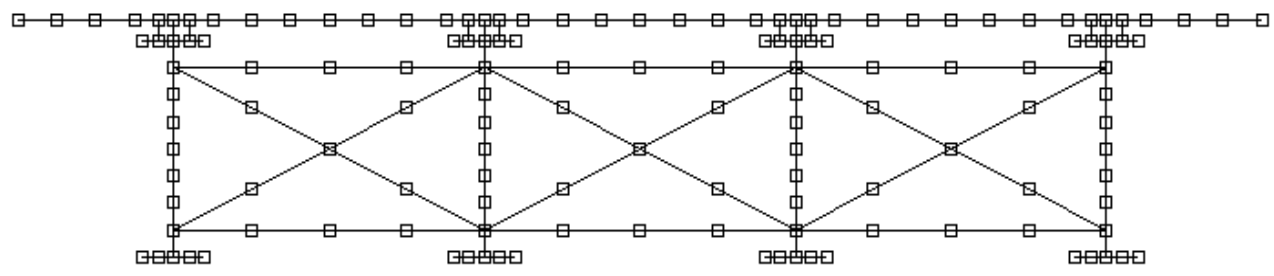

(a)

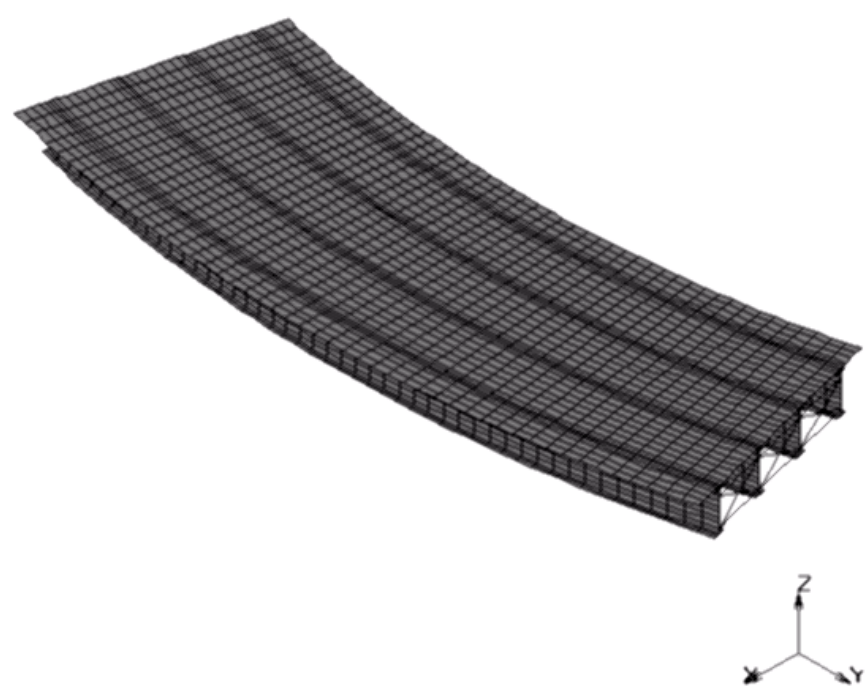

(b)

Figure 5: Bridge model: (a) finite element representation of bridge cross section;

(b) isometric view of the bridge

the uniform load is to be magnified. The impact factor for $L=24 \mathrm{~m}$ is 0.208 . Figure 6 shows the load case for maximum live load bending moment of a straight system of girders including impact. Shoring is assumed during the construction of the composite steel bridge.

\section{PARAMETRIC STUDY}

The present investigation considers the effect of a number of design variables on the response of the simply-supported composite curved girder systems including stiffness of cross frames, space between cross frames, degree of curvature, flange width, girder spacing and number of girders. An analytical approach using three dimensional finite element models is used for the present investigation to isolate which parameters are significant in the design sense for displacement and stresses.

A large number of finite element models were constructed, and normalizing techniques were used to help generalize the results. For instance, the study is interested in the effects that the addition of curvature has over the results from straight I-girder 


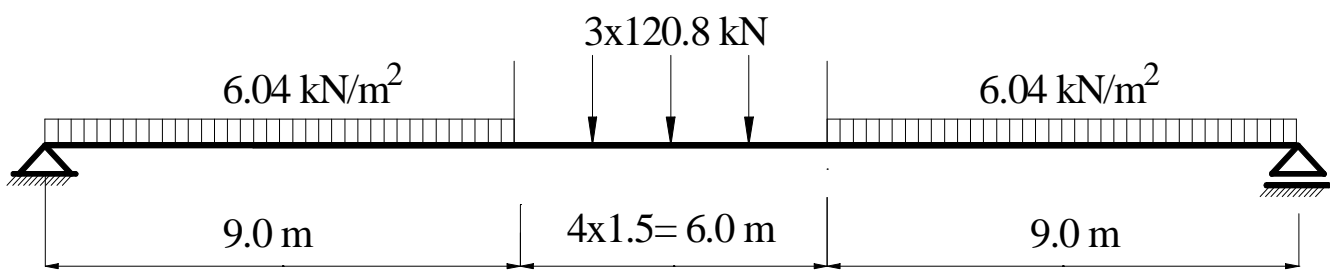

(a)

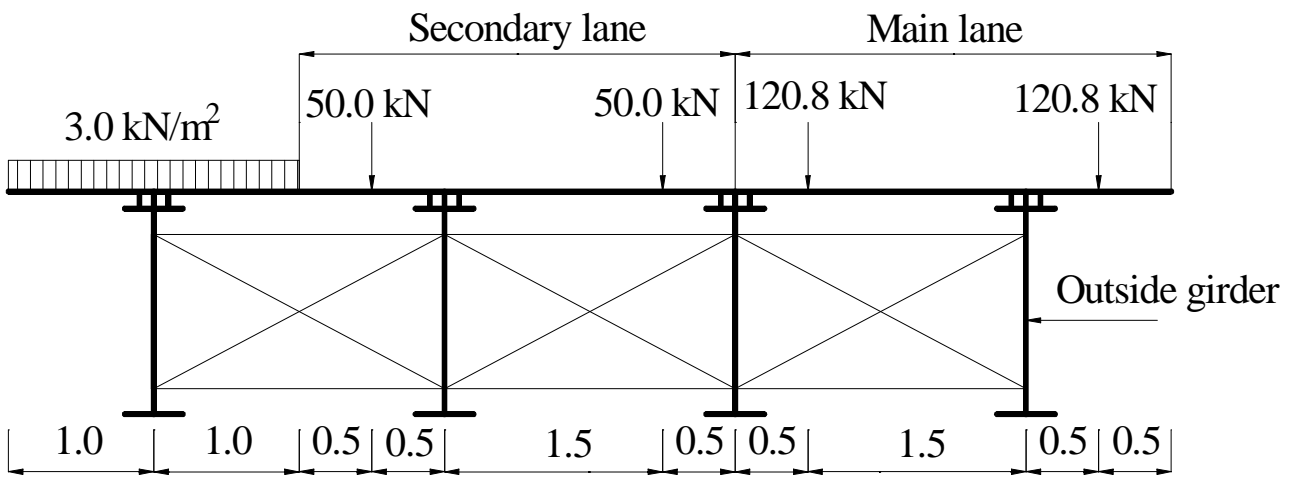

(b)

Figure 6: Bridge live load: (a) longitudinal cross section in the main lane for maximum bending moment; (b) lateral cross section at mid span.

systems with comparable dimensions so that the major axis (vertical) bending stresses resulting from the curved system were normalized to the bending stresses of the straight system with the same length and cross section dimensions. For the sake of comparison study, the length of the outside girder of the curved system is taken the same as that of the straight system $(24 \mathrm{~m})$ and the addition of other girders is on the inside of curvature to preserve a constant length and radius of curvature for the critical outside girder. The results of the critical outside girder of the curved system are compared to the similar one in the straight system. On the other hand, since significant warping stresses are not generally present in straight systems, the warping stress at the edge of the flange is generally normalized to the maximum tangential bending stress of the girder and referred to as the warping-to-bending stress ratio. Indeed, warping-tobending stress ratio $F_{w b}$, is an important issue in preliminary design purposes so that the American Association of State Highway and Transportation Officials (AASHTO) [13] mandates the $F_{w b}$ to be $\leq 0.50$. When investigating the influence of one parameter on the behaviour of composite system, other parameters are kept constant.

\section{RESULTS AND DISCUSSIONS}

For all models, both tangential stresses and vertical deflections at outer edge, middle and inner edge of the tension flange of the outside girder are calculated with the 
physical and mechanical properties mentioned above. The warping stress is estimated as one half of the difference between the outer and inner edge stresses. The warping-tobending stress ratio is calculated by dividing the warping stress to the maximum tangential stress at the middle of the bottom flange at critical section. The following description summarizes the effects that the parameters mentioned previously have on the composite curved girder system.

\subsection{Stiffness Of Cross Frames And L/R Ratio}

According to the Egyptian Code of Practice (ECP) for steel construction and bridges [14], the maximum slenderness ratio $\left(\lambda_{\max }\right)$ for roadway bridge members, roadway bridge bracings and building bracings in compression should not exceed 110, 140 and 200, respectively. So, when investigating the effect of stiffness of cross frames on the behaviour of a composite girder system, three different slenderness ratios are considered in this study. Also, three span-to-radius of curvature ratio, $L / R=0.1,0.3$ and 0.5 in addition to straight girder with $L / R=0.0$ are studied.

Figure 7 shows the warping-to-bending stress ratio $\left(F_{w b}\right)$ along the span of the outside girder of a curved bridge system along the span for $L / R=0.5$. It is shown that the warping stress is proportional to the bending stress i.e., $F_{w b}$ increases towards the maximum vertical bending moment at mid span and decreases towards the zero bending moments or end supports in simply supported beam. Also, from Fig. 7 it can be inferred that at the cross frame locations, the maximum tensile stresses are at the outer edge of flange and the minimum tensile stress at the inner edge of the flange. However, in the intervals between cross frames, the direction of the bimoment is reversed and the highest stresses occur on the inside edge of the flanges so the sign of the $F_{w b}$ is negative. On the other hand, it is shown that increasing the stiffness of cross

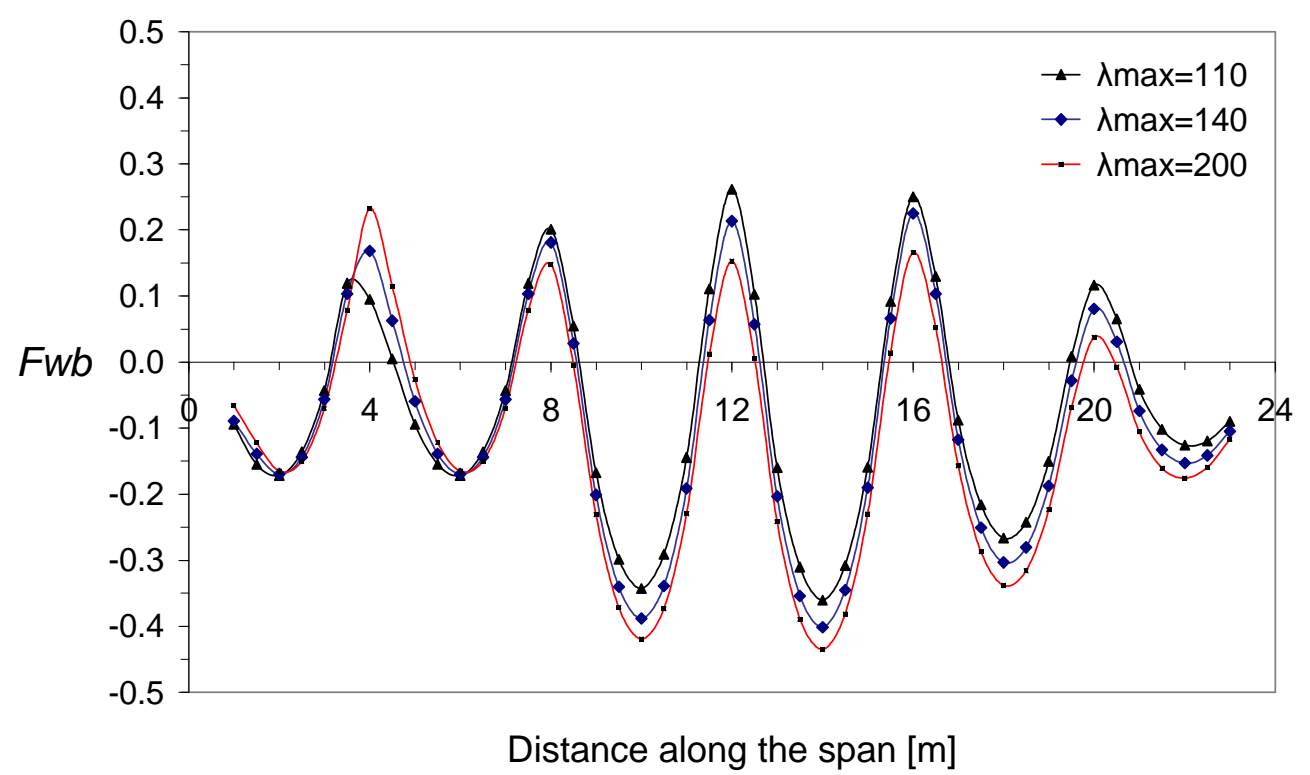

Figure 7: Warping-to-bending stress ratio $F_{w b}$ along the span of the outside girder $(L / R=0.5)$. 
frames or reducing the slenderness ratio of cross frames stabilizes the warping stress and decreases the maximum warping-to-bending stress ratio and equalizes the positive and negative warping stress. The maximum warping-to-bending stress ratio is obtained with maximum slenderness ratio, 200. It is interesting to mention that the figure is not symmetric due to the unsymmetrical boundary conditions at the end supports of the girders.

To show the effect of cross frame slenderness ratios on warping stress of curved composite girders, the relationship between warping-to-bending stress ratio $\left(F_{w b}\right)$ and the length-to-radius of curvature ratio $L / R$ are plotted in Fig. 8. It is shown that the warping stress for straight beams is very small and is due to live load and the effect of slenderness ratios of cross frames is negligible. However, cross frame stiffness has a considerable effect on warping stress for curved girder systems and the increase in cross frame stiffness leads to a decrease in warping stress. Also, for the same cross frame interval and stiffness, the warping stress increases with the decrease of radius of curvature.

Regarding the effect of cross frame slenderness ratios on the displacement of curved composite girders, it is found that the vertical displacements of the outer edge of the curved girders are greater than those of the inner edge. Herein only the vertical displacements of the outer edge are plotted for brevity. Figure 9 plots the vertical displacement ratio of curved to straight girders of outer edge of the bottom flange and the length-to-radius of curvature ratio $L / R$ with different cross frame slenderness ratios. It is shown that the maximum vertical displacement of curved system increases with the decrease of radius of curvature. Also, it is shown that increasing the stiffness of cross frames reduces the vertical displacement of the outer edge of the curved girders. This effect is more pronounced for small radius of curvature. So, the stiffness of cross frames has negligible effect on the straight girder but has considerable effect on curved girders. For the sake of comparison, the cross frames with $\lambda_{\max }=140$ is used in investigating the effect of other parameters on the behaviour of curved composite girders. Also, the basic section is assumed for the reference straight system.

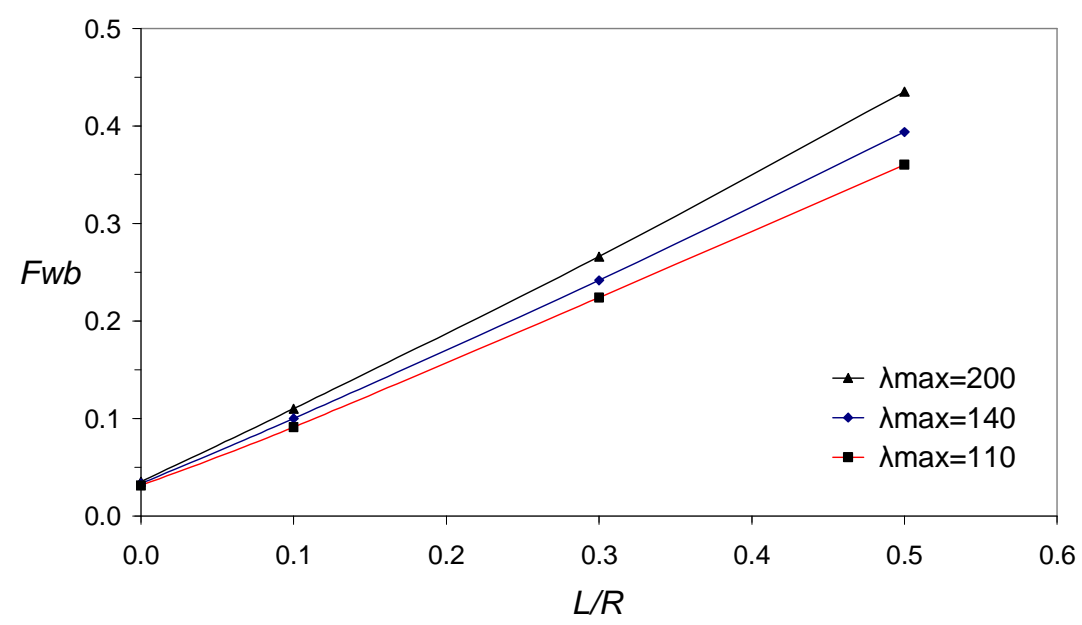

Figure 8: Effect of cross frame slenderness ratio on warping-to-bending stress ratio, $F_{w b}$. 


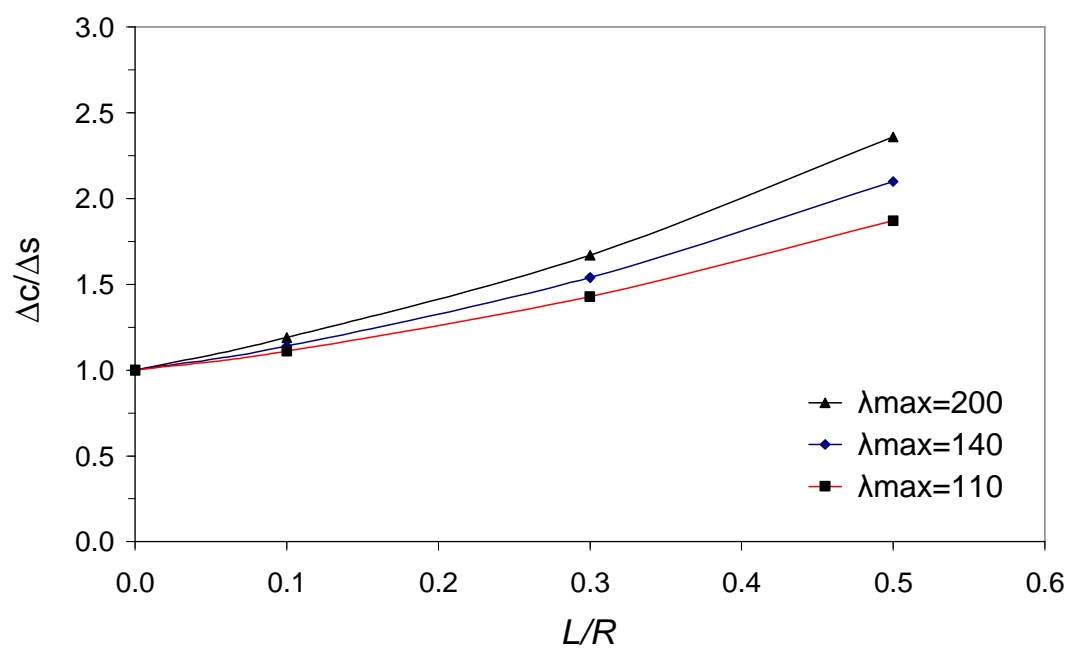

Figure 9: Effect of cross frame slenderness ratio on the maximum vertical displacement of outer edge of bottom flange.

\subsection{Cross Frame Intervals}

To determine the effect of space between cross frames on flange stresses and deflections in a curved system, models were created with varying cross frame intervals and curvatures. The space between cross frames $=L / N$ where, $L$ is the length of the outside girder and $N$ is the number of intervals of cross frames. The relationship between the number of cross frame intervals and warping-to-bending stress ratio $F_{w b}$, is illustrated in Fig. 10. It is shown that the number of cross frame intervals has a significant effect on $F_{w b}$. It is clearly shown that as the number of intervals increases the warping-to-bending stress ratio, $F_{w b}$ is decreased for all degrees of curvatures. The effect of cross frame intervals on $F_{w b}$ is more pronounced for high degree of curvature. Indeed, $F_{w b}$ is proportional to the square of cross frame spacing as noted in Eq. (8). It is important to mention that the number of cross frame intervals has a slight effect on the bending moment of bottom flange.

The relationship between the number of cross frame intervals and vertical displacement of the outer edge of the bottom flange for different degrees of curvatures is illustrated in Fig. 11. The vertical displacement of the curved system $(\Delta c)$ is normalized to that of the straight beam $(\Delta \mathrm{s})$ with six cross frame intervals (the space between cross frames is $4 \mathrm{~m}$ ). A displacement ratio of $\Delta \mathrm{c} / \Delta \mathrm{s}=1.0$ would represent a curved system with the same response as that of the comparable straight system. From Fig. 11, it is shown that increasing the number of cross frame intervals $N$, leads to a considerable decrease of the vertical displacement of the bottom flange for curved girders. Again, the number of cross frame intervals has significant effect for high degree of curvature and vice versa. Also, it is found that as the number of cross frame intervals increases a convergence of vertical displacement of outer and inner edges of the bottom flanges. So, the cross frame interval is an important parameter to change the warping stresses of curved girder system to an acceptable level. 


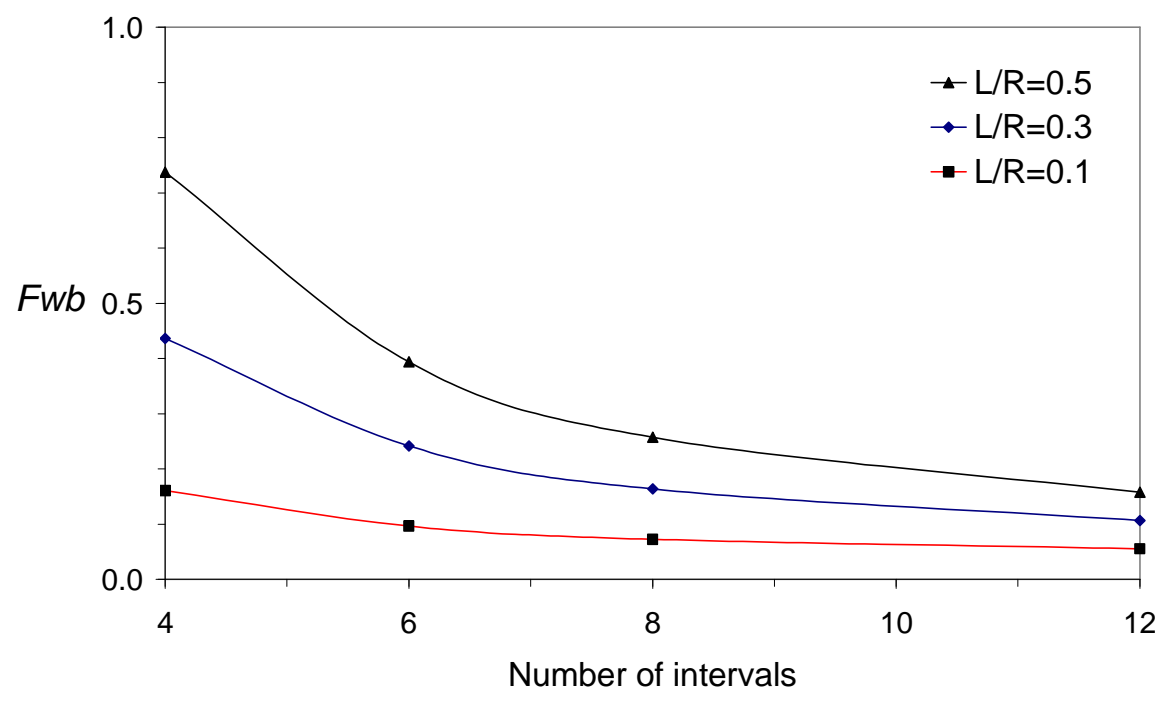

Figure 10: Effect of number of intervals of cross frames on warping-to-bending stress ratio, $F_{w b}$.

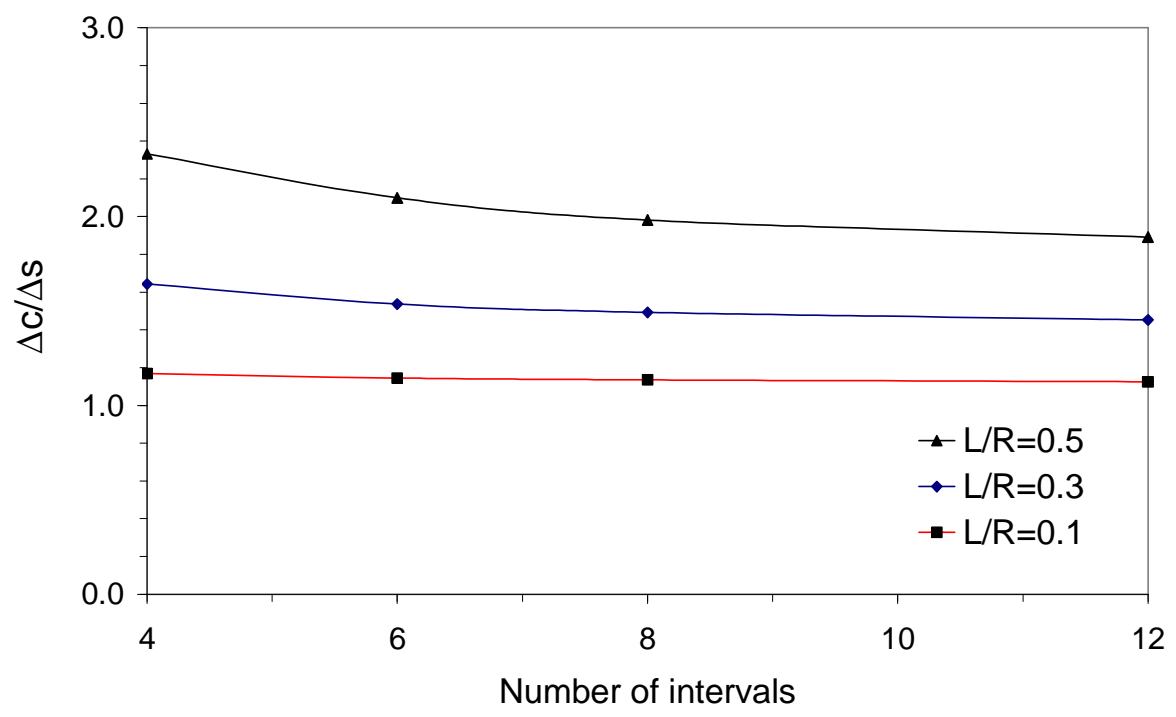

Figure 11: Effect of flange width on vertical displacement of outer flange edge.

\subsection{Flange Width}

To determine the effect of flange width on flange stresses in a curved system, models were created with varying bottom flange widths and curvatures. The increase in flange width leads to a decrease in the warping-to-bending stress ratio, $F_{w b}$ and the flange width is inversely proportional to the warping-to-bending stress ratio, $F_{w b}$ as illustrated in Fig. 12. Indeed, the increase in flange width leads to a decrease in both bending and warping stresses. However, the reduction of warping-to-bending stress 
ratio is due to the fact that the bending stress is inversely proportional to flange width as noted in Eq. (1), but the warping stress is inversely proportional to the square of the flange width as noted in equations (4) and (5). On the other hand, normalizing the results of the curved system with the corresponding straight girders with the same dimension gives straight lines which mean that the flange width does not affect the bending stress of a curved system with respect to the corresponding straight girders with the same dimensions.

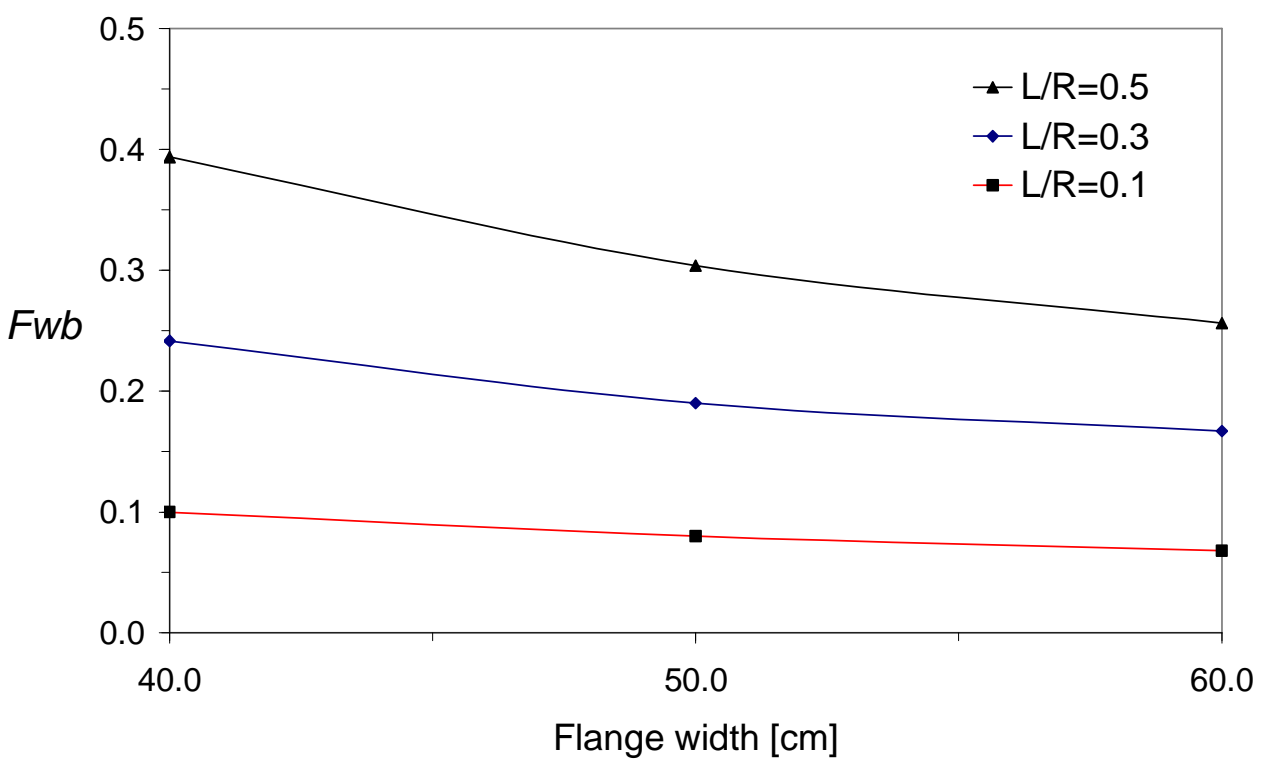

Figure 12: Effect of flange width on warping-to-bending stress ratio, $F_{w b}$

The relationship between the flange width and vertical displacement of the outer edge of the bottom flange for different bottom flange widths is illustrated in Fig. 13. The vertical displacement of the curved system $(\Delta \mathrm{c})$ is normalized to that of the straight beam $(\Delta \mathrm{s})$ with basic section i.e., flange width $B=40[\mathrm{~cm}]$. Again, the displacement ratio of $\Delta \mathrm{c} / \Delta \mathrm{s}=1.0$ would represent a curved system with the same response as that of the comparable straight system. From Fig. 13, it is shown that increasing the flange width leads to a considerable decrease of the vertical displacement of the outer edge of bottom flange for curved girders. Also, this leads to a convergence of the vertical displacement of outer and inner edges. So, flange width has a significant effect on warping-to-bending stress ratio and is taken into account in equations (8) and (9) for curved I-girder system.

\subsection{Number Of Girders AND Girder Spacing}

To determine the effect that the number of girders in a curved system has on the bending and warping stresses, a series of models were developed with 4, 5 and 6 girders with varying curvatures. The models were created by keeping the spacing between girders constant and adding girders on the inside of curvature, thereby increasing the width of the system but preserving a constant length and radius of 
curvature for the critical outside girder. For systems with slight curvature, the effect was found to be negligible on both bending and warping stresses. However, as curvature increases, the addition of girders slightly reduces the effect of curvature as demonstrated in Fig. 14. This is due to the fact that as the number of girders is increased, the width of the system and therefore the lateral and torsional stiffness of the system as a whole are increased. Similar results are obtained for the effect of number of girders on the vertical displacement of the curved system.

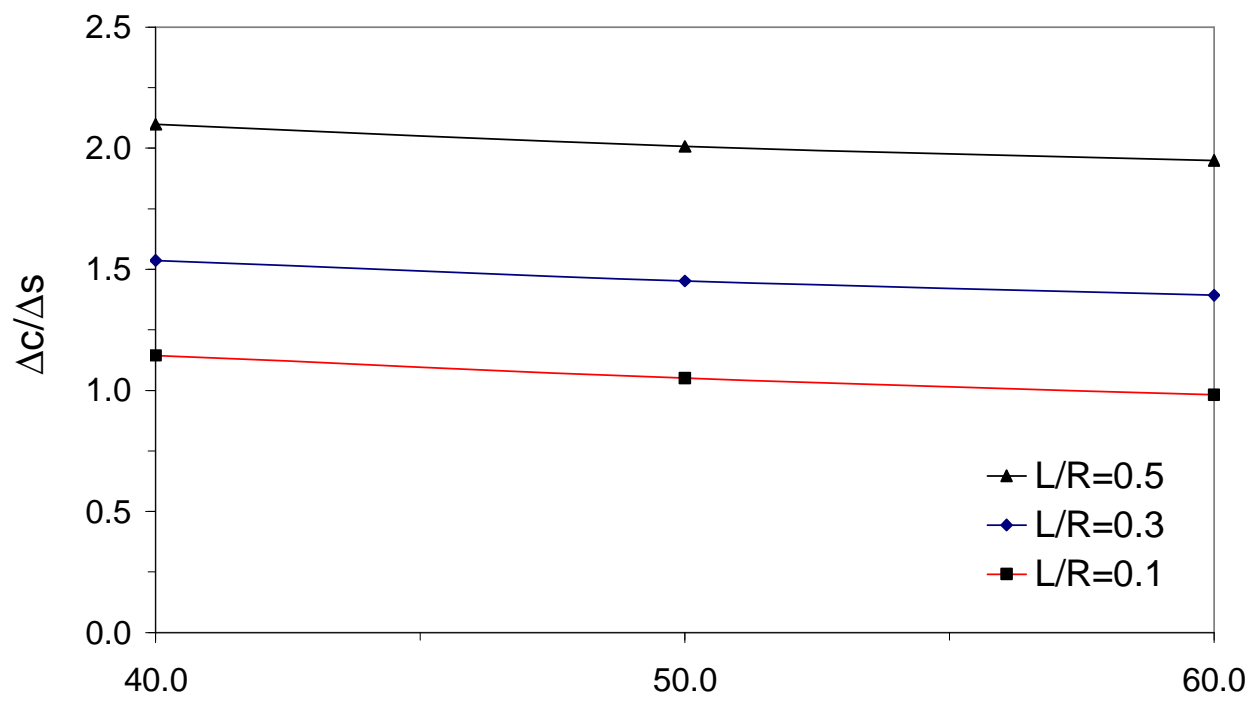

Flange width $[\mathrm{cm}]$

Figure 13: Effect of flange width on vertical displacement of outer flange edge .

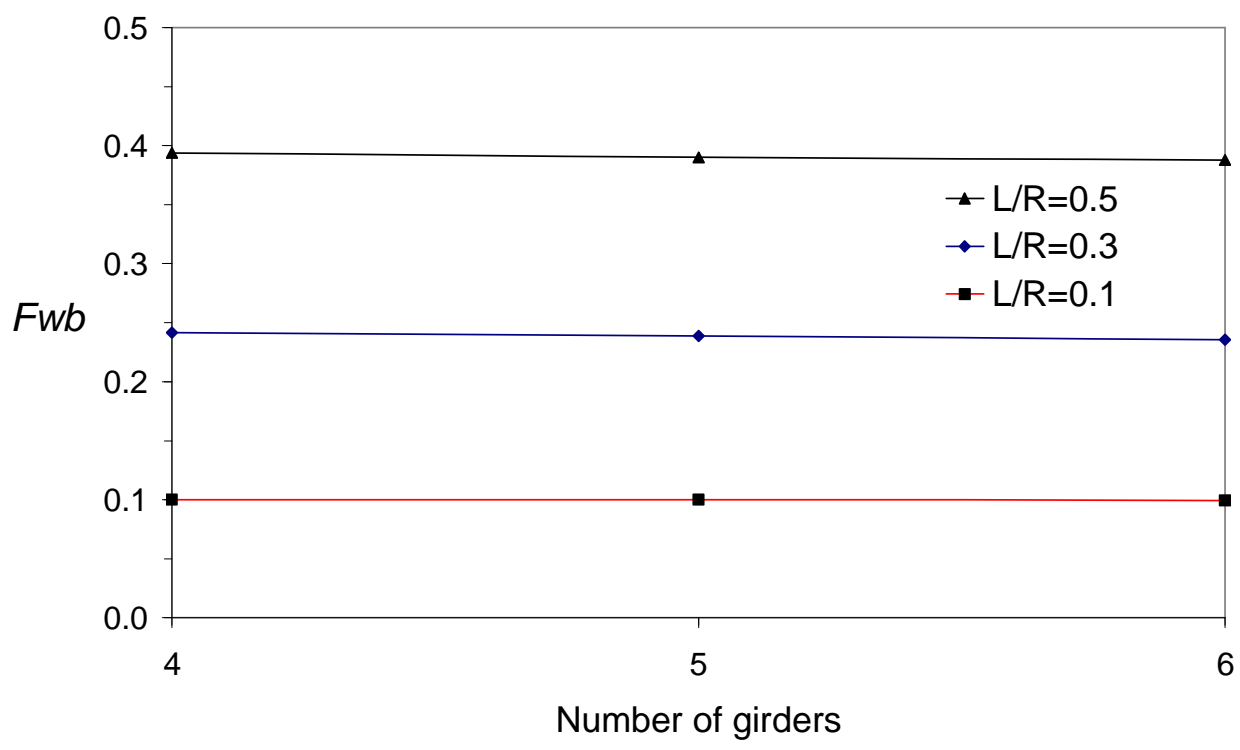

Figure 14: Effect of number of girders on warping-to-bending stress ratio, $F_{w b}$. 
To determine the effect that girder spacing has on the behaviour of a curved system, the spacing between adjacent girders was varied from $2[\mathrm{~m}]$ to $2.5[\mathrm{~m}]$ and 3.0 $[\mathrm{m}]$ with the same cross section for different curvatures. The increase in girder spacing leads to an increase in the resulting vertical bending moment and consequently an increase in the resulting warping stresses of the girder. Also, the increase in girder spacing increases the resulting vertical deflections of the bottom flanges of the girder. Indeed, the results obtained are similar to that obtained in Fig. 14. It is of interest to mention that the increase in girder spacing increases both warping and bending stresses proportionally so that warping-to-bending ratio would be kept constant. Then, the girder spacing does not affect the $F_{w b}$ and will not be included as a parameter in the final preliminary design equation.

\subsection{Cross Frame Interval Equation}

A comparison of the results of warping-to-bending stress ratio $F_{w b}$, obtained using the finite element analysis to those obtained using equations (8) and (9) for different span-to-radius of curvature ratios, $L / R$ are listed in Table 1. It is shown that the results obtained using Eq. (8) agree well with the finite element results for $L / R=$ 0.1 but overestimate the $F_{w b}$ for greater radii of curvatures. Also, Eq. (9) provides higher values than those of Eq. (8) for all values of curvatures. Another thing is that equations (8) and (9) do not take the effect of slenderness ratio of cross frames into consideration. So, Eq. (8) can be used for curved composite systems constructed with shoring with low degree of curvature $L / R \leq 0.1$ with normal cross frame slenderness ratio, $\lambda_{\max }=140$. To take the effect of slenderness ratio, $\lambda_{\max }$, the following equation is suggested to be used for $L / R \leq 0.1$.

$$
l=\left(\frac{5}{3} \sqrt{\frac{\lambda_{\max }}{140}} F_{w b} R b_{f}\right)^{1 / 2},
$$

where $l$ is the space between cross frames and $F_{w b}, R$ and $b_{f}$ are as defined in Eq. (8). For higher curvatures, $L / R>0.1$, it is suggested to change the continuous bending moment $M_{f}$, in Eq. (6) from $q l^{2} / 10$ to $q l^{2} / 12$, thus Eq. (8) becomes as follows:

$$
l=\left(2 F_{w b} R b_{f}\right)^{1 / 2},
$$

and when including the slenderness ratio of cross frames, Eq. (10) becomes as follows:

$$
l=\left(2 \sqrt{\frac{\lambda_{\max }}{140}} F_{w b} R b_{f}\right)^{1 / 2} .
$$

The results of warping-to-bending stress ratio $F_{w b}$, obtained using the finite element analysis and those obtained using equations (10) and (12) for different span-toradius of curvature ratios $L / R$, are listed in Table 2a for various cross frame slenderness ratios. Also, the results obtained for various cross frame intervals are listed in Table 2b. In Table 2a, it is clearly shown that equation (10) gives values that compares well with the finite element method for low curvature, $L / R \leq 0.1$, however, it 
gives un-conservative values for high degree of curvature. On the contrary, equation (12) underestimates the values of $F_{w b}$ for low degree of curvature. However, the results match those of the finite element for high degree of curvature, especially for $\lambda_{\max } \leq 140$. In Table $\mathbf{2 b}$, the same observation is clearly seen except for the results of four cross frame intervals (space between frames $=6[\mathrm{~m}]$ ) which is large and not recommended in curved girder systems. So, it is recommended to use equation (10) for low degree of curvature $(L / R \leq 0.1)$ and equation (12) for high degree of curvature $(L / R>0.1)$.

Table 1: Comparison of warping-to-bending stress ratio obtained by finite element analysis to those obtained using equations (8) and (9).

\begin{tabular}{|c|c|c|c|}
\hline \multirow{2}{*}{$\mathrm{L} / \mathrm{R}$} & \multicolumn{3}{|c|}{ Warping-to-bending stress ratio $\left(F_{w b}\right)$} \\
\cline { 2 - 4 } & Equation (8) & Equation $(9)$ & Finite element \\
\hline 0.1 & 0.1000 & 0.1184 & 0.1000 \\
0.3 & 0.3000 & 0.3555 & 0.2420 \\
0.5 & 0.5000 & 0.5919 & 0.3940 \\
\hline
\end{tabular}

Table 2a: Comparison of warping-to-bending stress ratio obtained by finite element to those obtained using equations for various cross frame slenderness ratios.

\begin{tabular}{|c|c|c|c|c|}
\hline \multirow{2}{*}{$L / R$} & \multirow{2}{*}{$\lambda_{\max }$} & \multicolumn{3}{|c|}{ Warping to bending stress ratio $\left(F_{w b}\right)$} \\
\cline { 3 - 5 } & & Equation (10) & Equation (12) & Finite element \\
\hline \multirow{3}{*}{0.1} & 200 & 0.117 & 0.100 & 0.110 \\
& 140 & 0.098 & 0.084 & 0.100 \\
& 110 & 0.087 & 0.075 & 0.091 \\
\hline \multirow{4}{*}{0.3} & 200 & 0.352 & 0.300 & 0.266 \\
& 140 & 0.294 & 0.250 & 0.242 \\
& 110 & 0.261 & 0.224 & 0.224 \\
\hline 0.5 & 200 & 0.586 & 0.500 & 0.435 \\
& 140 & 0.491 & 0.417 & 0.394 \\
& 110 & 0.370 & 0.370 & 0.360 \\
\hline
\end{tabular}

Table (2b): Comparison of warping-to-bending stress ratio obtained by finite element to those obtained using equations for various cross frame intervals.

\begin{tabular}{|c|c|c|c|c|}
\hline \multirow{2}{*}{$L / R$} & \multirow{2}{*}{$\begin{array}{c}\text { Cross } \\
\text { frame } \\
\text { intervals }\end{array}$} & \multicolumn{3}{|c|}{ Warping to bending stress ratio $\left(F_{w b}\right)$} \\
\cline { 3 - 5 } & 4 & Equation (10) & Equation (12) & Finite element \\
\hline \multirow{3}{*}{0.1} & 6 & 0.221 & 0.188 & 0.161 \\
& 8 & 0.098 & 0.084 & 0.100 \\
& 4 & 0.055 & 0.047 & 0.063 \\
\hline 0.3 & 6 & 0.662 & 0.563 & 0.437 \\
& 8 & 0.294 & 0.250 & 0.242 \\
& 4 & 0.166 & 0.141 & 0.144 \\
\hline 0.5 & 6 & 1.103 & 0.938 & 0.738 \\
& 8 & 0.491 & 0.417 & 0.394 \\
& 8 & 0.276 & 0.235 & 0.237 \\
\hline
\end{tabular}




\section{CONCLUSIONS}

Finite element modeling of structural steel-concrete composite beams curved in plan is presented in this paper. Shoring is assumed to be used during construction and live loads according to ECP are taken into consideration in the analysis. A parametric study of the effect of cross frames on the behaviour of composite steelconcrete girders is studied. The concrete deck slab and both steel webs and flanges are modelled using shell elements. Both studs and cross frames are modelled using beam elements. The accuracy of the finite element results are checked via comparing the numerical results to experimental results obtained by other authors. The study includes not only the displacements but also the tangential stresses through the inner edge, middle and outer edge of the tension flange along the span of the critical outside girder.

Based on the above results, it can be concluded that slenderness ratio of cross frames, cross frame spacing, radius of curvature, span length and flange width have greatest effect on warping-to-bending stress ratio. It is shown that equations which can be used for composite girders subjected to non-composite dead loads and recommended by other authors may give inaccurate results for curved composite systems constructed with shoring. Also, they do not take the slenderness ratio of cross frames into consideration. However, a modification is recommended to Eq. (8) to take into account the slenderness ratio of cross frames. Equations (10) and (12) are proposed for the preliminary design of cross frame spacing and warping-to-bending stress ratio. The accuracy of the results using the new equations is checked for various variables. It is of interest to mention that equation (10) is recommended for low degree of curvature $(L / R \leq 0.1)$ and Eq. (12) for high degree of curvature $(L / R>0.1)$. It is recommended that the maximum slenderness ratio of cross frames should not exceed 140. Furthermore, the recommended equations overestimate the values of warping-tobending stress ratio for large distance between cross frames. So, the distance between cross frames in curved systems should be ranged from 3 to $5 \mathrm{~m}$.

\section{REFERENCES}

[1] Baskar, K., Shanmugam, N. E., and Thevendran, V.: "FInITE-ELEMENT ANALYSIS OF STEEL-CONCRETE COMPOSITE PLATE GIRDER”, J. Structural Engineering, Vol. 128 (9), pp. 1158-1168 (2002).

[2] Nasr, A. M., Amer A. H., Saleh M. M. and AbuHamd M. H.: "SimPliFIED LOAD DISTRIBUTION FACTORS FOR CURVED STEEL I-GIRDER BRIDGES BASED ON ECP LIVE LOADS", Eleventh International Colloquium on Structural and Geotechnical Engineering, $11^{\text {th }}$ ICSGE, Cairo, Egypt,17-19 May (2005).

[3] Xanthakos, P. P.: "THEORY AND DESIGN OF BRIDGES", John Wiley and Sons, Inc., Chapter 13, 1443 pp., (1994).

[4] Thevendran, V., Shanmugam, N. E., Chen, S. and Richard-Liew, J. Y.: "EXPERIMENTAL STUDY ON STEEL-CONCRETE COMPOSITE BEAMS CURVED IN PLAN", J. Engineering Structures, Vol. 22, pp. 877-889, (2000).

[5] Salem, A.H., El- Aghoury, M. and Moustafa, T. S.: "FInITE ELEMENT MODELING OF COMPOSITE STEEL-FREE DECK BRIDGES CURVED VERSUS STRAIGHT BRIDGES", International Colloquium on Structural and Geotechnical Engineering, $11^{\text {th }}$ ICSGE, Cairo, Egypt, 17-19 May (2005). 
[6] Schelling, D., Namini, A. H., and Fu, C. C.: "Construction efFeCts ON BRACING ON CURVED I GIRDERS”, J. Structural Engineering, ASCE, 115(9), pp. 2145-2165, (1989).

[7] Heins, C. P. and Jin, J. O.: "LIVE LOAD Distribution ON BRACED CURVED IGIRDERS", J. Structural Engineering, ASCE, 110(3), pp. 523-530, (1984).

[8] Yoo, C. H., and Littrell, P. C.: "CROSS-BRACING EFFECTS IN CURVED STRINGER BRIDGES”, J. Structural Engineering, ASCE, 112(9), pp. 2127-2140, (1986).

[9] Davidson, J.S., Keller, M.A., and Yoo, C.H.: "CROSS-FRAME SPACING AND PARAMETRIC EFFECTS IN HORIZONTALLY CURVED I-GIRDER BRIDGES", $J$. Structural Engineering, ASCE, 122(9), pp. 1089-1096, (1996).

[10] MARC Analysis Research Corporation, Volumes; A, B, and C, Version 2001, (2001).

[11] MARC Analysis Research Corporation, Mentat User's Guide, Version 2001, (2001).

[12] EGYPTIAN CODE FOR FORCE AND LOAD COMPUTATION IN STRUCTURES AND BUILDINGS (ECP), 76 pp., (2003).

[13] American Association for State Highway and Transportation Officials, (AASHTO): "GUIDE SPECIFICATION FOR HORIZONTALLY CURVED HIGHWAY BRIDGES", Washington, D.C., (1996).

[14] EGYPTIAN CODE OF PRACTICE FOR STEEL CONSTRUCTION AND BRIDGES (ECP), Code No. (205), 255 pp., (2001).

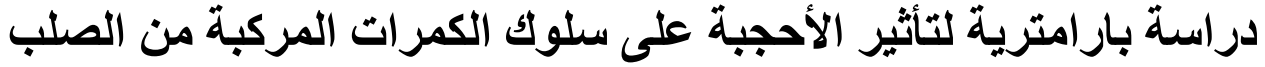

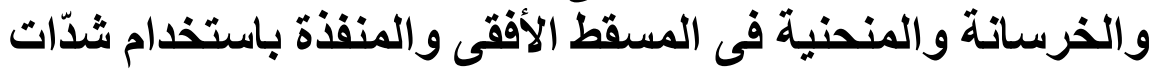

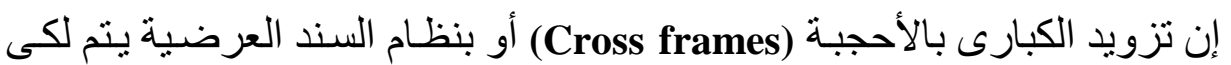

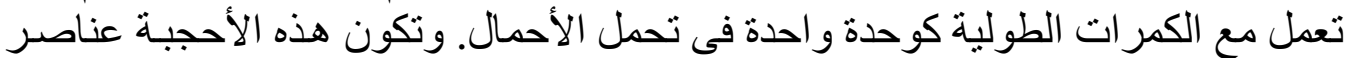

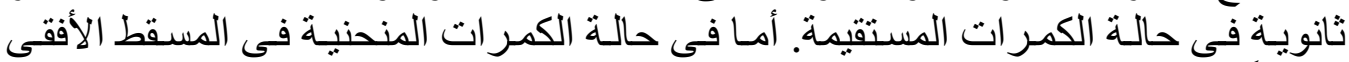

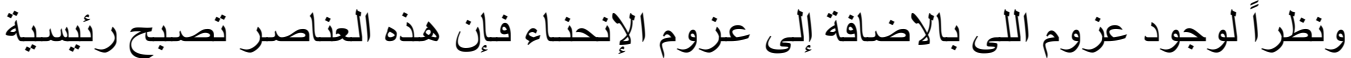

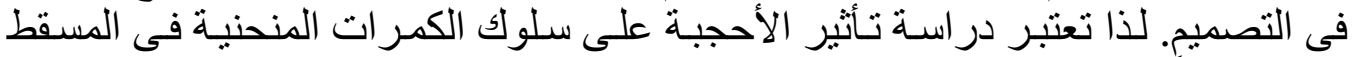

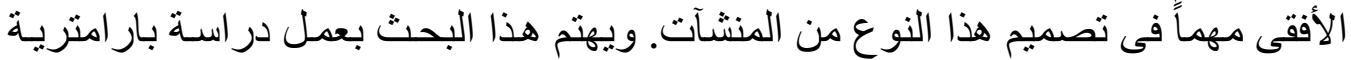

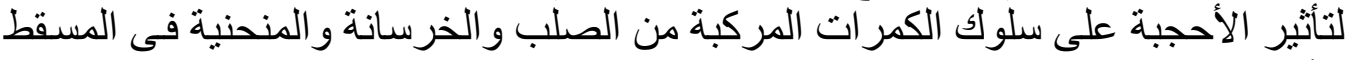

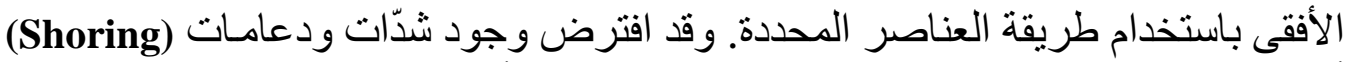

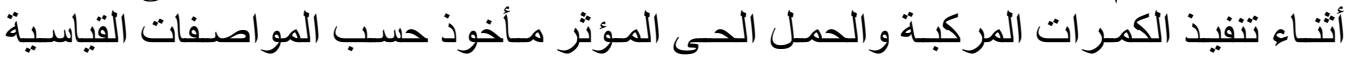

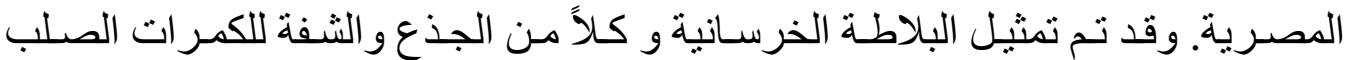

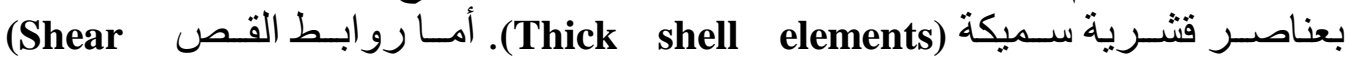

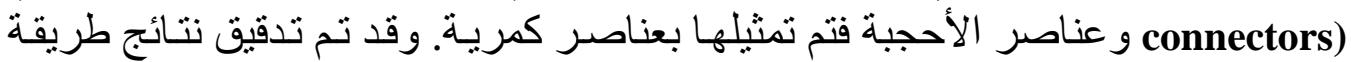

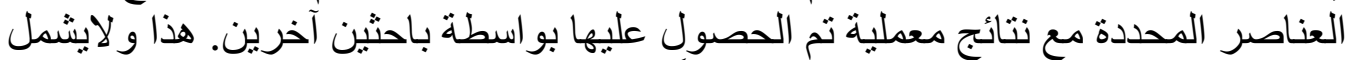

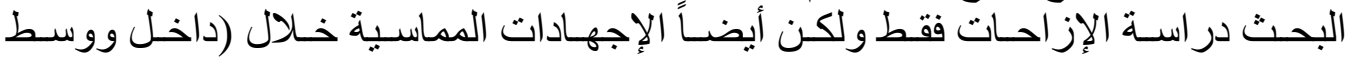


وخارج) الثفة السفلية و المعرضة للثند وذلك بطول الكمرة الخارجيـة الحرجـة من النظـام وقد وجد مـن النتائج أن نسبة النحافـة (Slenderness ratio) لعناصـر الأحجبـة

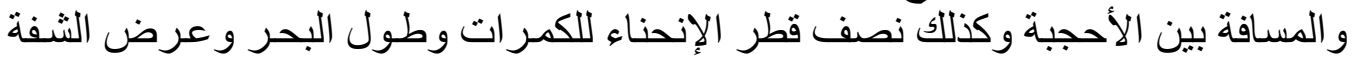

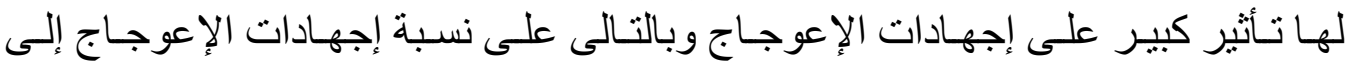

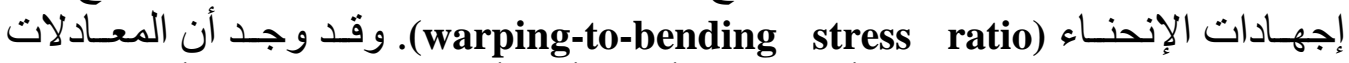

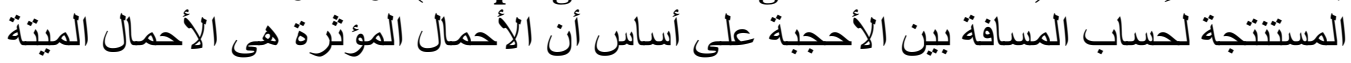

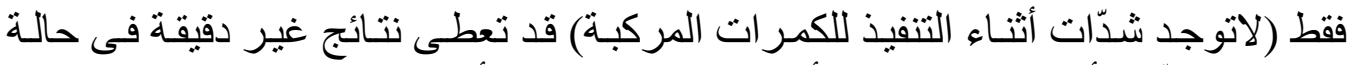

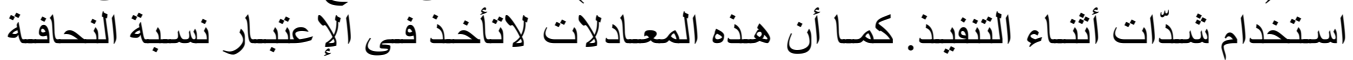

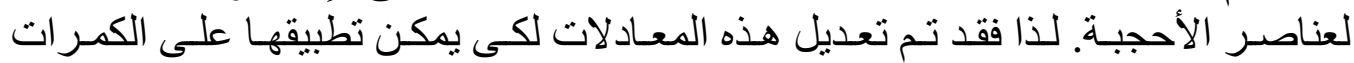

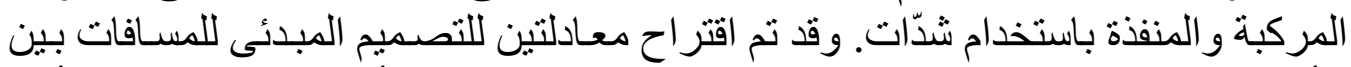

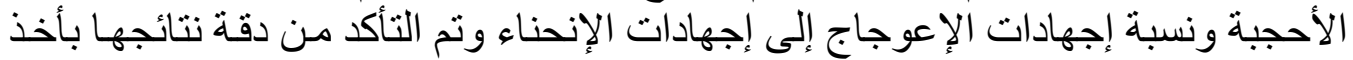

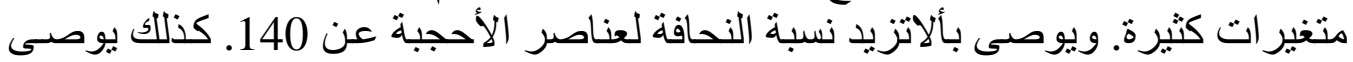

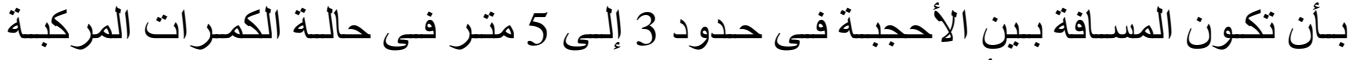
و المنحنية فى المسقط الأفقى. 